\title{
PAISAGEM E FENOMENOLOGIA DO LUGAR POÉTICO: IMAGINÁRIO ARBÓREO DO PARQUE DO FLAMENGO
}

Landscape and Phenomenology of the Poetic Place: Imaginário Arbóreo Park of Flamengo

Paisaje y Fenomenología del Lugar Poético: Imaginario Arboleo del Parque del Flamengo

\author{
Jorge Crichyno \\ Universidade Federal Fluminense (UFF)
}

\begin{abstract}
RESUMO
O tema tratado neste estudo refere-se ao lugar poético do imaginário arbóreo e suas repercussões e ressonâncias na paisagem, buscando elucidar a componente arbórea enquanto potência imaginal. As árvores constituem elementos naturais múltiplos na paisagem urbana, impregnados de significados simbólicos e capazes de evocar o imaginário dos sujeitos, despertando emoções e preenchendo de poética a cidade do Rio de Janeiro. Buscando compreender essa diversidade de sentidos, o estudo investiga a presença das árvores no Parque do Flamengo, desvendando os significados e valores simbólicos, a partir dos elos que se estabelecem com os sujeitos configurando uma fenomenologia poética do lugar arborescente. Desta forma, busca-se alcançar um dos principais objetivos deste trabalho que é o estudo do vegetalismo arbóreo em projetos urbanos, esperando que esta reflexão teórica venha a contribuir no sentido de sua valorização em paisagens urbanas.
\end{abstract}

Palavras-chaves: Fenomenologia; Lugar Poético; Imaginário Arbóreo; Parque do Flamengo.

\begin{abstract}
The theme addressed in this study refers to the poetic place of the arboreal imagery and its repercussions and resonances in the landscape, seeking to elucidate the tree component as an imaginal power. The trees are multiple natural elements in the urban landscape, impregnated with symbolic meanings and able to evoke the subjects' imagination, arousing emotions and filling the city of Rio de Janeiro with poetry. Seeking to understand this diversity of senses, the research investigates the presence of trees in the Flamengo Park, revealing the meanings and symbolic values, starting from the links established with the subjects, forming a poetic phenomenology of the arborescent place. In this way, it is sought to achieve one of the main objectives of this work, which is the study of tree planting in urban projects, hoping that this theoretical reflection will contribute towards its appreciation in urban landscapes.
\end{abstract}

Keywords: Phenomenology; Poetic Place; Arboreal Imaginary; Flamengo Park.

\section{RESUMEN}

Rev. Nufen: Phenom. Interd. | Belém, 11(1), 157-177, jan. - abr., 2019. 
El tema tratado en este estudio se refiere al lugar poético del imaginario arbóreo y sus repercusiones y resonancias en el paisaje, buscando dilucidar el componente arbóreo como potencia imaginal. Los árboles constituyen elementos naturales múltiples en el paisaje urbano, impregnados de significados simbólicos y capaces de evocar el imaginario de los sujetos, despertando emociones y llenando de poética la ciudad de Río de Janeiro.La investigación investiga la presencia de los árboles en el Parque del Flamengo, desvendando los significados y valores simbólicos, a partir de los eslabones que se establecen con los sujetos configurando una fenomenología poética del lugar arborescente. De esta forma, se busca alcanzar uno de los principales objetivos de este trabajo que es el estudio del vegetalismo arbóreo en proyectos urbanos, esperando que esta reflexión teórica venga a contribuir en el sentido de su valorización en paisajes urbanos.

Palabras claves: La fenomenología; Lugar Poético; Imaginario Arbóreo; Parque del Flamengo.

\section{INTRODUÇÃO}

Entrar em contato com o que existe de mais profundo nas coisas do mundo, e assim buscar o significado que nos une a elas, constitui a intenção de uma postura de investigação científica que se distancia dos métodos clássicos de estudo.

A motivação deste estudo vem do sentido de que este pensamento possa nos auxiliar com relação a uma mudança de perspectiva conferida à árvore pelos sujeitos na cidade. No contexto urbano, podemos perceber tanto a força quanto a grandeza de sua existência, seja na expressividade de sua presença em contraste com a paisagem criada, ou pela evocação de sua imagem em termos de aspectos simbólicos.

Um dos maiores representantes da natureza nas cidades são as árvores, por sua presença na paisagem e pelo elo natural que estabelecem com os sujeitos. A presença das árvores na cidade é uma forma de reaproximar os sujeitos da natureza aliando o prosaico ao poético, retomando a ligação existente desde seus ancestrais.

A árvore é um elemento extremamente enriquecedor da paisagem e pode simbolizar a relação entre céu e terra. Segundo Gordon Cullen (1983), entre os diversos elementos naturais que compõem a paisagem urbana, a árvore é, sem dúvida, o mais frequente, e a relação entre sujeitos, árvores e lugares da cidade tem uma longa e considerável tradição.

A relevância da presença das árvores no ambiente urbano é sempre muito ressaltada em função dos benefícios ecológico-ambientais que (re)presenta para a cidade e para os sujeitos (Sattler, 1992; Detzel, 1992; Furtado, 1994). Nas últimas décadas, trabalhos científicos têm destacado que a contribuição das árvores para as cidades também reside nos valores psicológicos que elas trazem e nos valores e significados que presentificam 
para a população, questões apontadas com menor frequência (Schroeder, 1990; Dwyer, 1994).

A compreensão desses valores é fundamental para o entendimento das relações lugar-árvore-sujeito. A partir do desenvolvimento de estudos no campo da Psicologia Ambiental, muitas foram as contribuições trazidas à compreensão dos benefícios que a vegetação proporciona aos sujeitos. Os estudos realizados por Stiegler (1990) e por Hull (1992) buscaram aferir os benefícios da arborização urbana que foram atribuídos pelos sujeitos, tendo sido constatada sua importância como um símbolo de memórias passadas, destacando-se como marco referencial e como elemento que concede importância ao lugar.

Indagamos, então, qual outro elemento na paisagem urbana é capaz de provocar imagens poéticas tão fortes em nossa interioridade? A árvore urbana apresenta uma grande força e multiplicidade de significados emocionais e simbólicos para os sujeitos no contexto da vida do mundo cotidiano urbano, possibilitando efeitos relaxantes à população em geral, e é associado à crença espiritual.

Segundo Bachelard (2001), a busca da imersão na dimensão fenomenológica da árvore na cidade possibilita entender que toda imagem poética nasce a partir de "uma cooperação entre a imaginação das formas e a imaginação material dos sujeitos" (BACHELARD, 2001, p. 4). Esse autor distingue em toda obra poética, dois tipos de impacto sobre a nossa consciência: a ressonância que é o resultado da exuberância da obra e que atua sobre nossos afetos e emoções e; a repercussão que opera em camadas mais profundas do "Ser", que nos emociona provocando verdadeira transformação em nós.

Bachelard considera que um observador só compartilha do entusiasmo de uma cidade por intermédio de imagens poéticas que nele repercutiram. A linguagem poética possibilita lidar com a linguagem científica, de modo que, a dimensão poética constitua uma referência que expressa a verdade do "Ser". A linguagem poética constitui a possibilidade da experiência do desvelamento dos fenômenos e sua relação com o "Ser-Mundo", evocando ou modificando nossa relação com o mundo da percepção e da ação.

Segundo Edgard Morin (2001), atualmente:

É possível um diálogo entre ciência e literatura (poema), e isso porque a ciência nos revela um universo fabulosamente poético ao redescobrir problemas filosóficos capitais: “O que é o homem?”, "Qual o seu lugar?”, “Qual o seu destino?”, “O que se pode esperar dele?" (p. 42).

Com efeito, esse autor nos mostra que o antigo universo da ciência era uma máquina perfeita, como uma espécie de relógio permanente e, agora, nos demos conta de 
que o real, aparentemente sólido e evidente, foi dissipado pelo olhar da microfísica, e que, do ponto de vista do cosmos, o tempo e o espaço, se misturaram.

Para Albert Einstein (1931), a imaginação é criadora e inventa novos sentidos. A imaginação é mais importante que o conhecimento. O conhecimento é limitado. A imaginação envolve o mundo, estimulando o progresso e dando origem à evolução. Ela é, de maneira rigorosa, um fator real na pesquisa científica.

Pelos caminhos da imaginação, as forças oníricas e as pulsões inconscientes nos conduzem para uma fusão com as coisas, de modo a pertencer e habitar o mundo. $A$ imaginação torna-se então prospectiva, agenciando "a aventura da percepção" e o devaneio proporciona a abertura ao mundo e nos faz habitar o mundo. "Todo o espaço realmente habitado traz a essência da noção de habitar, aconchego acolhedor da casa" (Bachelard, 1957, p. 55). As imagens que emergem do devaneio humano constituem valores a partir dos quais nós somos criados. Para Bachelard "a imagem tem dupla realidade: uma psíquica e outra física" (Bachelard, 2001, p. 5).

Neste sentido, o poeta pode reestabelecer uma ligação entre os sujeitos e o lugar através do devaneio poético da árvore como símbolo urbano, estabelecendo na obra de arte uma relação de pertencimento, uma espécie de enraizamento do sujeito com o lugar na paisagem urbana, resgatando um sonho devaneador dos elos orgânicos entre sujeitos e sua cidade. Manoel de Barros (2015) expressa perfeitamente em seu poema o devaneio da obra de arte utilizando-se do significado da imagem pelo "Ser":

Não tenho bens de acontecimentos.

O que não sei fazer desconto nas palavras.

Entesouro frases. Por exemplo:

- Imagens são palavras que nos faltaram.

- Poesia é a ocupação da palavra pela Imagem.

- Poesia é a ocupação da Imagem pelo Ser

[...] Todos os caminhos - nenhum caminho

Muitos caminhos nenhum caminho - a maldição dos poetas [...]

Retrato quase apagado (Barros, 2015, p. 72).

Conforme Werther Holzer (2012), "lugar é um fenômeno experiencial, ao que, desde o início, é uma parte essencial da vida. O lugar está incorporado à anatomia ontológica de toda a experiência humana" (Holzer, 2012, p. 6). A noção de lugar pode variar de conteúdo mais concreto ao mais metafórico, pois segundo este autor o objeto da descrição ("lugar mimético") do lugar pode ser transformado em uma descrição relacionada à experiência de vida no lugar ("lugar hermenêutico").

Rev. Nufen: Phenom. Interd. | Belém, 11(1), 157-177, jan. - abr., 2019. 
O lugar na Geografia Humanista Cultural, conceituado por Yi-Fu Tuan (1975) a partir de seu artigo "O Lugar: uma perspectiva da experiência" considera que:

O lugar é conhecido não só através dos olhos e da mente, mas também através de modos de experiência mais passivos e diretos que resistem à objetivação. Conhecer um lugar totalmente significa compreendê-lo de uma forma abstrata e, ao mesmo tempo, conhecê-lo como uma pessoa conhece a outra. Num nível teórico elevado, os lugares são pontos em um sistema espacial. No extremo oposto, são fortes sentimentos viscerais (p. 152).

A questão do lugar, a partir dos conceitos de Yi-Fu Tuan, Ribeiro (1995) considera que "os lugares de pertencimento necessitam ser refeitos e expandidos diante do extraordinário nível atingido nas culturas contemporâneas" (Ribeiro, 1995, p. 157). O lugar arbóreo como símbolo de pertencimento, com suas qualidades de abrigo devem ser compartilhadas pelos sujeitos.

Assim, este estudo tem como tema a árvore como lugar poético, buscando compreender a participação do elemento arbóreo como potência imaginal na paisagem de nossas cidades. O interesse para escolha deste tema surgiu da reflexão de que as árvores possuem um valor como (con)figurador simbólico do lugar urbano. Para o desenvolvimento desta pesquisa, é necessário identificar o significado simbólico e poético da imagem-árvore para os sujeitos.

O conceito de potência imaginal relaciona-se a eventos, de uma realidade que Ihe é própria, situada em outro nível que o dos eventos do mundo exterior. Situado no limiar entre a percepção e o intelecto, afina-se com as duas constituições, a matéria e a substância intangível, sem, no entanto, pertencer a nenhuma das duas. Esse termo termina por ser mais preciso do que o termo imagem, pois envolve muitos significados.

Primordialmente, acentuamos que o presente trabalho se fundamenta a partir de uma visão urbanística e paisagística no contexto dos estudos urbanos, descobrindo novos olhares e novas interpretações, investigando as ressonâncias e as repercussões do imaginário arbóreo e o seu papel na paisagem urbana. Neste sentido, pretendemos abordar algumas ressonâncias e repercussões do imaginário arbóreo existente no Parque do Flamengo no que se refere às formas de apropriação de usos de lazer e recreação dos sujeitos e da população em geral.

A incursão neste campo temático objetivou alinhar-se à ideia de que questões subjetivas de valores e significados das árvores urbanas precisam ser consideradas importantes nos espaços livres públicos urbanos. Acreditamos que para melhor compreendermos o imaginário arbóreo como lugar na paisagem urbana, faz-se necessário a

Rev. Nufen: Phenom. Interd. | Belém, 11(1), 157-177, jan. - abr., 2019. 
sua discussão, através do estudo do complexo imagético que o compõe. Compreendemos por complexo imagético da árvore o sistema das imagens arbóreas de origem virtual em nossa interioridade: memoriais, simbólicas, poéticas e imaginais que compõem o imaginário arbóreo.

Desse modo, trabalhamos aqui supondo a premissa de que a análise e interpretação de fontes poéticas (poemas) podem elucidar e revelar os dinamismos indutores do imaginário arbóreo urbano, a partir dos significados e valores simbólicos presentes na fenomenologia das estruturas imaginantes da árvore como lugar poético no Parque do Flamengo.

No que tange aos estudos urbanos, não podemos deixar de considerar que o foco e o objeto final serão sempre os sujeitos e as suas necessidades e expectativas ao vivenciar o lugar urbano da paisagem, os aspectos imaginais da árvore como lugar na paisagem do Parque do Flamengo, presentificam o imaginário arbóreo e seu rebatimento simbólico na poética urbana, constituindo um tema rico de significado, mas ainda pouco explorado.

A questão central que norteia a reflexão deste estudo consiste em buscar a compreensão do papel do imaginário arbóreo urbano nas modulações do lugar poético dos sujeitos no Parque do Flamengo, em suas expectativas e necessidade de vivenciar a cidade e sua paisagem.

\section{FENOMENOLOGIA E POÉTICA DE UM LUGAR ARBORESCENTE: O PARQUE DO FLAMENGO}

O Parque do Flamengo fala por si só e para milhares de cariocas, nas (re)presentações que fazem do país e da cidade, enunciando um significado poético. As memórias e os sonhos de futuro por ele evocados têm tamanha força que transcendem fronteiras. Foi graças a essas memórias, e aos sonhos que o Rio de Janeiro é capaz de fazer sonhar, que a própria cidade foi reconhecida recentemente pela UNESCO como Patrimônio da Humanidade na categoria de Paisagem Cultural.

A construção do parque reuniu em sua defesa o que a cidade teve de melhor em termos de excelência técnica, estética, administrativa e política. Por isso mesmo, as ameaças a que muitas vezes a área foi e ainda é submetida, subvertendo seu sentido primeiro - tanto de espaço fraterno como de lugar coletivo e público - exigem que nos lembremos que ela é o resultado de uma série de lutas e conquistas. Segundo Margareth Pereira (2015), "pode-se dizer que o germe do Parque do Flamengo foi a criação do Museu de Arte Moderna (MAM).

Rev. Nufen: Phenom. Interd. | Belém, 11(1), 157-177, jan. - abr., 2019. 
A partir de 1958, Burle Marx começou a articular os jardins fragmentários nas imediações do MAM e do Monumento aos Pracinhas (1959) até o bairro da Glória. O Parque do Flamengo é um parque à beira mar, construído sobre um extenso aterro hidráulico, criado nos anos 1960 e inaugurado em 1965 às margens da Baía de Guanabara (Figura 1).

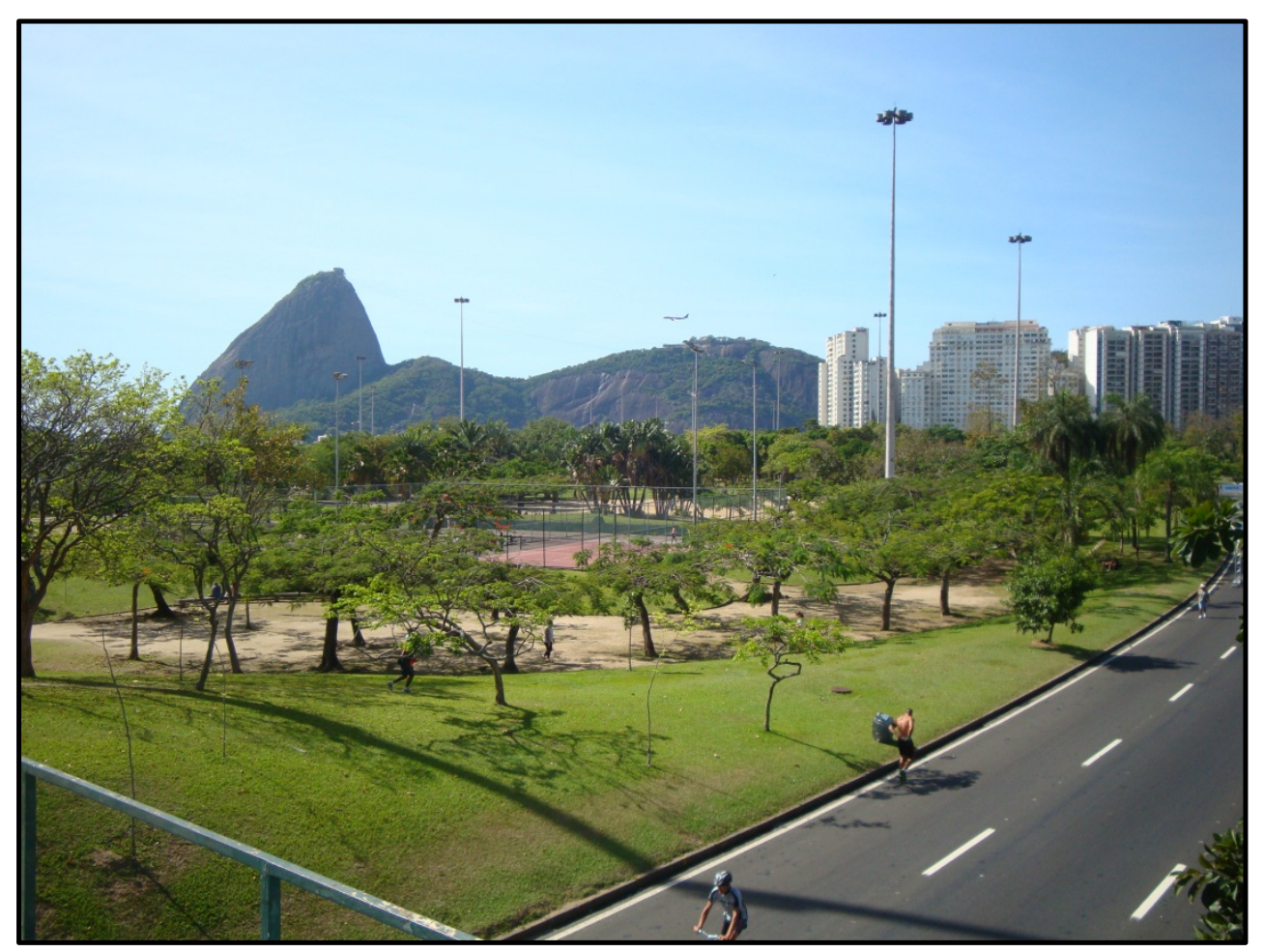

Figura 1: Vista do Parque do Flamengo. 2013. Foto de Jorge Crichyno.

Uma questão que se impõe diz respeito aos obstáculos epistemológicos envolvidos na abordagem do tema, o que nos induz a algumas reflexões e considerações sobre os caminhos metodológicos adotados neste trabalho. Bachelard em sua obra Poética do Devaneio cita o questionamento feito por Jules Laforgue: "Método, Método, que queres de mim? Bem sabes que comi do fruto do inconsciente" (Laforgue, 1887 citado por Bachelard, 2001, p. 1).

Como afirma Heidegger (2009), fazer ciência é uma forma de "Ser" no mundo, portanto, parte sempre de uma escolha, de uma intencionalidade do pesquisador, ainda que sejam feitas a partir de mera intuição. Neste sentido, a ciência não possui neutralidade, pois ela é também uma forma de se portar diante do mundo.

A ciência só se origina pela existência do sujeito enquanto "Ser" e suas indagações diante daquilo que se manifesta, mas não qualquer fenômeno, pelo contrário, aqueles fenômenos que despertam interesse, surpresa e espanto. A ciência ao partir da própria experiência para existir e para se desenvolver, significa compreender que é a experiência que mobiliza o fazer científico, suscitando as perguntas que colocam em

Rev. Nufen: Phenom. Interd. | Belém, 11(1), 157-177, jan. - abr., 2019. 
movimento o pensamento, as reflexões e o conhecimento científico num contínuo fluxo de vivências.

A necessidade de escolha de um caminho metodológico impõe uma série de reflexões, para as quais encontramos alento no pensamento esclarecedor de Merleau-Ponty (1963). Esse autor defende que a ciência clássica trata todo "Ser" como "objeto em geral" e, complementa sua ideia indicando ser preciso que o pensamento científico seja substituído pela concepção de que devemos retornar à dimensão de que

há (il $y$ a) prévio, local, isto é, sobre o solo no mundo sensível e do mundo lavrado tais como são em nossa vida, para o nosso corpo, não esse corpo possível que é sustentado como uma máquina de informação, mas este corpo atual que digo meu, a sentinela que se porta silenciosamente sob a minha palavra e sob meus atos (p. 9).

Numa perspectiva fenomenológica, o filósofo francês ainda descreve que "[...] o mundo é não aquilo que penso, mas aquilo que eu vivo" (Merleau-Ponty, 1994, p. 22). Tratase de restituir o mundo vivido, ou seja, esse mundo primordial antes da reflexão e da ciência, considerada por Silva (2013) em seu artigo "Manipular ou habitar? Merleau-Ponty e o paradoxo da ciência".

Por que, então, esse retorno à experiência originária do mundo e do espaço assume um alcance fenomenológico? Ou melhor, o que é a fenomenologia? Segundo David Cerbone (2013), em sentido geral, a fenomenologia é "o estudo dos fenômenos, onde a noção de um fenômeno e a noção de experiência, de um modo geral, coincidem. Prestar atenção à experiência em vez de àquilo que é experienciado é prestar atenção aos fenômenos" (Cerbone, 2013, p. 13). Ora, a experiência a qual nos referimos é precisamente aquela já enunciada por Merleau-Ponty (1994, p. 182):

A partir do momento em que a experiência é reconhecida como o começo do conhecimento, não há mais nenhum meio de distinguir um plano das verdades a priori e um plano das verdades de fato, aquilo que o mundo deve ser e aquilo que o mundo efetivamente é.

Portanto, o mundo é aquilo que eu experiencio e que é experienciado pelo outro. O geógrafo Eric Dardel (1899-1967) reforça essa mesma concepção ao situar que o "Ser como o homem e o mundo como o lugar de vida de cada ser, de cada homem, se constrói na relação Ser-Mundo" (Dardel, 1990, p. 3). Ora, essa compreensão pode ser tomada por uma ciência da Geografia como uma premissa significativamente decisiva. Há uma espécie, digamos, de "geograficidade" em cada sujeito na qual "ciência e filosofia são unidas" como

Rev. Nufen: Phenom. Interd. | Belém, 11(1), 157-177, jan. - abr., 2019. 
Dardel postula (Holzer, 2001, p. 144). A geograficidade, segundo Dardel, refere-se às várias maneiras pelas quais sentimos e conhecemos ambientes em todas as suas formas. $O$ que entra em jogo, aqui, é "o relacionamento com os espaços, os lugares e as paisagens, construídas e naturais que são as bases e recursos do homem e para as quais há uma fixação existencial" (Dardel, 1990, p. 42).

A categoria de lugar é ressignificada por Merleau-Ponty à luz da categoria de espaço, à medida que o filósofo fala de uma "espacialidade primordial" em que nosso corpo adere: "A experiência revela sob o espaço objetivo, no qual finalmente o corpo toma lugar, uma espacialidade primordial da qual a primeira é apenas o invólucro e que se confunde com o próprio ser do corpo" (Merleau-Ponty, 1994, p. 205). Isso pode ser ainda fundamentado no capítulo sobre o "Espaço" na Fenomenologia da Percepção que, conforme vimos, alude também à noção husserliana de "mundo vivido", noção essa retomada e aprofundada pelo fenomenólogo francês. Suas reflexões deixam claro que este mundo vivido é o lugar onde habita os homens. Consideramos que é necessário reaprender a ver o mundo e, consequentemente, o lugar.

Anne Buttimer (1979) vai ainda mais longe quando argumenta: "[...] se queremos compreender a experiência do outro - observar o mundo com os seus próprios óculos - é necessário entrar em diálogo com ele, o convidar a se revelar em seus próprios termos [...]" (Buttimer, 1979, p. 248).

Como compreende Merleau-Ponty (2000), o ato de ver estabelece o nosso lugar no mundo vivido, pois o modo como somos capazes de ver as coisas do mundo é determinada pelo que conhecemos e cremos. Isso tudo porque escreve nosso filósofo:

[...] todo o universo da ciência é constituído sobre o mundo vivido, e se queremos pensar a própria ciência com rigor, apreciar exatamente seu sentido e seu alcance precisamos primeiramente despertar essa experiência do mundo da qual é a expressão segunda (Merleau-Ponty, 1994, p. 19).

Maturana (1988) destaca a importância da linguagem na constituição da "realidade" no mundo da natureza e nas interações no espaço consensual da intersubjetividade dos sujeitos. Foerster (1974) também faz o mesmo, ampliando a afirmação de Maturana de que "tudo é dito por um observador" (Maturana, 1988, p. 42), acrescentando que "tudo que é dito é dito por um observador" (Foerster, 1994, p. 90). Nessa afirmação, Foerster considera como sendo essenciais para o sujeito, as suas experiências e os significados da linguagem em termos de visão de mundo (lugar).

Neste contexto de abordagem no campo científico, se insere o pressuposto da intersubjetividade a partir da ruptura entre as ciências do homem e as ciências da natureza 
como afirma Esteves de Vasconcellos (1995), "toda ciência é ciência humana da natureza" (Vasconcellos, 1995, p. 67).

Com base no conceito de "ciência novo-paradigmática" ou do "pensamento sistêmico", segundo essa autora, é possível distinguir três novos pressupostos teóricos paradigmáticos da ciência contemporânea emergente ${ }_{2}$ que são: a complexidade, a instabilidade e a intersubjetividade. Assim, na observação do fenômeno do "mundo-da-vida cotidiana", o sujeito-observador poderá perceber "em que circunstâncias o fenômeno acontece, verá relações intrassistêmicas e intersistêmicas, verá não mais um fenômeno, mas uma teia de fenômenos recursivamente interligados e, terá diante de si a complexidade do sistema" (Vasconcellos, 2013, p. 151).

Com relação à perspectiva de distinção sobre o possível dinamismo das relações existentes em determinado sistema, a autora considera que "o sujeito-observador estará vendo um processo em curso [...] com o qual não poderá pretender uma interação instrutiva, e estará assumindo a instabilidade" (Vasconcellos, 2013, p. 151).

E finalmente, por meio do reconhecimento da sua própria participação na constituição da "realidade", é necessário que "o sujeito-observador venha a se incluir verdadeiramente no sistema que distinguiu [...], e estará nesse espaço de intersubjetividade" (Vasconcellos, 2013, p. 151), percebendo seu acoplamento estrutural com a existência dos objetos no mundo. Paul Dell (1985) define o conceito de acoplamento estrutural como "o processo que nos dá o universo organizado em que vivemos, que organiza e constitui todos os sistemas complexos que existem, [...]" (Dell, 1985, p.12).

Maturana (1997), em A Ontologia da Realidade, denomina de "objetividade entre parênteses" (múltiplas verdades, diferentes narrativas), compreendendo que o processo de distinção que o observador realiza decorre do fato que o objeto passa a existir em relação a um observador a partir do momento que este o distingue. O que interessa não reside mais sobre "a realidade tal como ela existe, mas sobre a experiência, substitui-se a preocupação com a verdade pelo reconhecimento de múltiplas verdades" (Vasconcellos, 2013, p. 140141).

Deste modo, podemos entender que sem um sujeito-observador diante de um dado fenômeno, não poderá fazer referência a algo (determinado objeto da "realidade"), que seja existente da independência dele, a fim de conferir a validade de sua experiência de algo situado na "vida-do-mundo cotidiano". Segundo a autora, "não há outra forma de validar, a não ser por meio de outra experiência" (Vasconcellos, 2013, p. 140).

Neste sentido, recuperamos os princípios da fenomenologia para o estudo do lugar que são: descrição, intencionalidade, redução fenomenológica e intersubjetividade. Consideramos que estes princípios apontam outra forma de investigar e interpretar as coisas, os homens e o mundo (lugar). Merleau-Ponty (1994) propõe descrever as coisas, os

Rev. Nufen: Phenom. Interd. | Belém, 11(1), 157-177, jan. - abr., 2019. 
objetos como mundo físico natural, os sujeitos a partir de seu próprio corpo buscando ampliar o entendimento de sujeito social. Ora, o princípio da descrição aqui ressaltada não se refere apenas ao sujeito que pesquisa, mas aquele que vive o fenômeno, uma vez que a reflexão tenta restituir o vivido em questão, procurando descrevê-lo o mais adequadamente possível. Já o princípio da intencionalidade não separa o sujeito do objeto, o ser do mundo e sim o ser envolto no mundo (Ser-Mundo).

Por outro lado, a redução fenomenológica busca perceber a realidade primeiramente como concebe o "senso comum", ou seja, como um voltar às coisas mesmas. Assim, o princípio da redução é uma espécie de admiração diante do mundo e nos remete às experiências vividas pelos sujeitos antes das reflexões filosóficas e científicas que recaem sobre eles. Finalmente, o princípio da intersubjetividade pode ajudar-nos a entender a herança sociocultural e o papel assumido no mundo vivido de cada dia, sugerindo situações herdadas que circunda a nossa vida diária.

É na relação intersubjetiva que o lugar vai sendo percebido e construído, enquanto lugar de vida, enquanto espaço vivido; não o ambiente real ou lógico em que as coisas se dispõem, mas o "[...] meio pelo qual a posição das coisas se torna possível" (Merleau-Ponty, 1994, p. 328). Sendo assim, o lugar passa a ser percebido por quem o habita, a partir das relações dos sujeitos com as coisas dos lugares que conhecem e que vivem.

Nossa posição enquanto pesquisador deve situar, hermeneuticamente, aqueles que estão vivenciando o fenômeno do espaço ou do lugar (Relph, 1978). Vemos, portanto, na fenomenologia uma maneira propositiva no sentido de iniciar uma investigação de caráter científico, tentando restituir o mundo vivido em questão onde "[...] a fenomenologia desafia cada sujeito a examinar sua própria experiência, a tornar-se sujeito mais do que objeto de pesquisa" (Buttimer, 1976, p. 277). É nessa direção que nosso trabalho visa partir, então, dos fundamentos dessa escola filosófica na qual se torna possível encontrar diversos geógrafos humanistas culturais, que a partir da década de 1950, tentaram trazer estas reflexões para a Geografia. Ora, é Merleau-Ponty quem já apontara duas tendências básicas em curso do movimento fenomenológico, ou seja, a fenomenologia é

[...] uma filosofia transcendental que coloca em suspenso, para compreendê-las, as afirmações da atitude natural, mas é também uma filosofia para a qual o mundo já está sempre 'ali', antes da reflexão, como uma presença inalienável, e cujo esforço todo consiste em reencontrar este contato ingênuo com o mundo, para dar-Ihe enfim um estatuto filosófico (Merleau-Ponty, 1994, p. 1).

Rev. Nufen: Phenom. Interd. | Belém, 11(1), 157-177, jan. - abr., 2019. 
Segundo Jean-François Lyotard (s.d.), a fenomenologia considera que toda ciência se inicia estabelecendo "uma rede de essências, obtidas por variações imaginárias, que serão depois confirmadas por variações reais: as experimentações" (Lyotard, citado por Holzer, 2010, p. 46).

$\mathrm{Na}$ atualidade, a tendência a uma abordagem não racionalista tem sido desenvolvida em diversas áreas. Escolhemos a linha da Geografia Humanista Cultural, por exemplo, orientada nesta direção, que aponta no sentido da consideração de uma perspectiva apoiada na significação da experiência do "mundo-da-vida cotidiana". Através do exame do fenômeno no mundo vivido e da fenomenologia existencial, partimos do princípio da unidade e indivisibilidade da experiência do "Ser" e da importância para nossa existência do significado atribuído ao lugar pelas intenções humanas (Relph, 1976).

Relph (1978), tanto quanto Dardel concebe o lugar como as bases da existência humana, considerando que "[...] lugares têm paisagem, e paisagem e espaços têm lugares [...]" (Relph, 1978, p. 16). Este autor considera nesta relação o lugar como o mais fundamental conceito porque focaliza espaço e paisagem em torno das intenções e experiências humanas. Assim sendo, lugar é o mundo vivido, distinto e singularizado porque atraem e concentram nossas intenções.

Nesta concepção fenomenológica, nos apoiamos em Bachelard (1960) que desenvolveu uma metodologia ainda inovadora elaborando um tratamento mais sensível da postura científica. Seu aporte teórico apresenta-se como um caminho para investigação do significado profundo dos objetos, entre os quais o que nos interessa no caso de nossa pesquisa, o estudo do lugar poético no imaginário arbóreo. A obra desse autor influenciou no estudo do imaginário através de textos poéticos; trabalhos esses que se expandem para o tratamento de valores e significados urbanos. Tais textos fazem uso da literatura no intuito de captar a essência do pensamento do autor e seus mais profundos significados na criação da imagem poética.

A ótica da fenomenologia do imaginário delimitada por Gaston Bachelard (18841962) utiliza dos recursos fenomenológicos para pesquisar o mundo estético a partir do que denominou "a fenomenologia da imaginação material". Este filósofo da ciência realizou a "poético-análise" dos quatro elementos constituintes da phýsis: água, ar, terra e fogo, denominando tal dialética do pensamento de "imaginação da matéria". A partir de textos literários poéticos, ele realizou a cartografia dos movimentos da imaginação, lançando a premissa de que tais recursos estariam ancorados nas raízes da materialidade do mundo.

No estudo do imaginário arbóreo urbano, recorrer à sensibilidade poética, do "estado poético" (Morin, 2001), em busca da concepção de artistas e poetas, é sem dúvida, uma forma de captar sentimentos, emoções e desejos vivenciados pelos sujeitos. De alguma forma, é trazê-los à tona em (re)presentações das mais variadas possibilidades de 
expressão artística (pintura, literatura e música), propiciando a compreensão de tal modo, que sirvam de instrumento no caminho da construção do meio urbano em que vivemos.

$\mathrm{Na}$ Literatura, os poetas e os poemas "falam do limiar do 'Ser' e, é capaz de revelar a verdade do seu íntimo" (Bachelard, 2004, p. 2), traduzindo o valor que está ao seu redor, como o significado de um elemento da paisagem para os sujeitos - a árvore. Dessa forma, ao expressar a capacidade de apreender e transmitir os mais diversos sentimentos dos sujeitos e dos grupos sociais, o poeta e o poema nos ensinam sobre o nosso próprio modo de ser e de nos relacionarmos com os outros. A Literatura, em especial, o poema não apenas produz (re)presentações através de obras poéticas sobre as transformações da urbe, como também revela seus sonhos, desejos e utopias.

Ao incursarmo-nos pelos meandros do imaginário arbóreo é fundamental a visualização dos diferentes planos imagéticos que o permeiam. Este procedimento sugere abranger desde a imagem pura da árvore às suas ressignificações no contexto cultural e urbano, o que implica que este estudo transite por searas de caráter diferenciado. Em função disto, optou-se pelo seu desenvolvimento a partir de um nível epistemológico que provê um suporte para o tratamento de análise do espaço urbano que é o Parque do Flamengo.

Compreendemos esse nível como fundamental pelo fato de o tema aqui discutido tratar da árvore no ambiente urbano, mas que, não podemos deixar de considerar o aporte da abordagem poética e simbólica arquetípica, extremamente importante no caso do imaginário arbóreo. Esta proposta de abordagem surge, como uma tentativa de abarcar a complexidade imanente da potência imagética da árvore na paisagem. Ressaltamos que essa abordagem espelha os valores epistemológicos referentes ao imaginário.

Encontramos suporte também nos estudos de Augustin Berque, quando ele aponta "a falta de uma abordagem ontológica na Geografia e vice-versa. Relacionamo-nos com o mundo e com as coisas, o que implica uma complexidade que não pode ser vislumbrada apenas no âmbito espacial, como ocorre frequentemente também no campo do planejamento urbano" (Berque, 2000, p. 9).

As reflexões originadas dos conceitos berquianos de predicado e sujeito vêm confirmar nosso caminho metodológico. O primeiro diz respeito ao que, pelo nosso modo de ver, depositamos na natureza das coisas e do mundo, que nos possibilita acessá-las, qualificando-as pela relação que temos com elas. O predicado inclui a nomeação que damos às coisas, enfim, todos os signos e símbolos que a elas atribuímos. O sujeito é o que as coisas e o mundo são neles mesmos, em sua identidade próxima de seu próprio "topos". Segundo o autor, a realidade do mundo só pode ser compreendida como uma relação entre predicado e sujeito. Berque em sua obra O Ecúmeno (2000) aborda a dimensão medial 
entre o homem e a terra. Isso quer dizer justamente que não podemos ter uma visão unilateral do mundo, que ele é o resultado da sobreposição dessas duas instâncias.

\section{CONCLUSÃO}

Este estudo se fundamentou a partir de uma visão paisagística no contexto dos estudos urbanos, que buscou descobrir novos olhares e novas interpretações sobre a fenomenologia do lugar poético referente ao imaginário arbóreo do Parque do Flamengo.

Nesse sentido, a árvore apresenta-se como símbolo potente e seguro, que nos guia e permanece como objeto confiável, o que nos faz elevá-la à categoria de símbolo estável. Essa estabilidade simbólica, uma das maiores dentre outros elementos da paisagem, hoje se coloca como um fator fundamental, visto que na pós-modernidade, enfatiza-se a instabilidade do significado dos símbolos e encontra-se aguçada a nossa habilidade de inverter sinais e signos, incorporá-los num contexto diferente transformando sua referência (Daniels \& Cosgrove, 2002).

A árvore urbana representa, portanto, um arquétipo expressivo, o que Dorfles (1975) aponta como sendo a qualidade natural do símbolo, visto que, na atualidade, temos a máquina ocupando amplamente esses espaços. Assim, o significado arbóreo no contexto da poética do lugar relacionado ao imaginário urbano está acima, muitas vezes, do tempo ou dos estilos arquitetônicos, urbanísticos e paisagísticos. O símbolo arbóreo não é apenas múltiplo, mas evoca também a capacidade de flutuar entre significações diametralmente opostas, tais como: vida e morte, sagrado e profano, adequação e rebeldia, refúgio e perigo, dia e noite, infernal e celeste, ar e terra. Essas interações estão relacionadas às modulações da imagem-árvore que fazem do devaneio do lugar poético arbóreo um devaneio particular, que excede em suas repercussões e ressonâncias ao infinito e acolhe os temperamentos mais divergentes dos sujeitos urbanos e suas estruturas sociais e culturais.

Na perspectiva de estudar a poética do lugar arbóreo no Parque do Flamengo a partir das nuanças da imagem-árvore em termos da construção de uma paisagem significativa, a análise das estruturas imaginantes nos revelou como a árvore é capaz de inflar a paisagem de valores e significados simbólicos profundos, existenciais, possibilitando ser experienciados pelos sujeitos urbanos. O reforço e a garantia da presença desses valores apresentados a partir das estruturas imaginantes possibilitou um caminho de pesquisa, que acreditamos no intuito de alcançar as condições apontadas por NorbergSchulz (1980) na busca de uma qualidade da paisagem.

As condições de maleabilidade das sensações, da escolha e multiplicidade que as árvores trazem para a paisagem, pela afetividade que despertam, são pontos importantes para o desenvolvimento de paisagens significativas, como é o exemplo do Parque do 
Flamengo, para se compreender o real sentido do habitar. A habilidade do poeta da paisagem, despertada para o potencial imagético da árvore, pode favorecer para que ele consiga dinamizar a transparência desses valores, assegurando paisagens urbanas mais sensíveis, interessantes e poéticas.

Para alcançar uma paisagem significativa, aquela com a qual os sujeitos se identificam e na qual se sentem à vontade no reconhecimento do sentido do lugar poético, se torna necessária a percepção do significado simbólico e suas conexões experienciais. Como argumenta Lynch (1990), imprimem na paisagem a marca de eventos humanos conectados com os sujeitos da cidade. É como atingir a correspondência entre o corpo individual e o corpo urbano, fazendo com que os sujeitos se reconheçam numa cidade e, reconheçam essa cidade como individualidade. Vemos que a árvore urbana se apresenta como uma possibilidade efetiva de vivenciar esse propósito.

Entendemos como paisagem significativa aquela que fala diretamente à alma dos cidadãos e que facilita o seu estado de devaneio poético. A existência da árvore urbana é um intensificador desse fator, que pode ser realçado pela sua presença, de forma a possibilitar a transmissão de sua mensagem de maneira mais intensa e plena, revelando mais diretamente o caráter de sua alma.

Sentimentos de afeição que surgem entre os sujeitos urbanos e determinadas espécies arbóreas também influem na definição de uma paisagem significativa, como é o caso do objeto de estudo do Parque do Flamengo.

A árvore da cidade urbaniza essas cosmicidades. Ter o domínio dessas essências expostas no "Ser arborescente" e suas repercussões ou ressonâncias na paisagem e nos sujeitos que habitam tais lugares poéticos, constitui um aporte fenomenológico fundamental para compreendermos o devaneio do imaginário arbóreo na poética da paisagem.

No nosso estudo foram consideradas as reflexões teóricas e os procedimentos metodológicos que tiveram por base a concepção filosófica de cunho fenomenológico. Foi proposta a premissa de que a análise e a interpretação de fontes poéticas literárias (poemas) podem elucidar e revelar os dinamismos indutores do imaginário arbóreo urbano. Com base no enfoque fenomenológico, foram identificados alguns significados e valores simbólicos presentes nas estruturas imaginantes da árvore como lugar poético no Parque do Flamengo.

Acreditamos na elaboração de que para novos projetos na paisagem, as árvores sejam consideradas fundamentais, pois elas são capazes, como nos informa Brosse (1998), de comunicar por canais que ainda não podemos explorar. Tirando partido de sua utilização em projetos urbanos, podemos ascender a esses canais, estabelecendo conexões 
simbólicas de apego aos sujeitos, que não seriam possíveis por meio de outro elemento urbano.

Em seu artigo Árvore e Alma, Roberto Gambini (1997) destaca a importância da empatia entre árvores e sujeitos, ao caracterizar uma profunda relação de identidade de lugar simbólico e poético, exemplificando que:

$\mathrm{Na}$ antiga tradição mitológica existem muitas versões da árvore da vida, da árvore do indivíduo, da árvore da sabedoria, da árvore do conhecimento do bem e do mal, da árvore do sacrifício, da verdade, da justiça, da felicidade, da iluminação, da árvore alquímica, filosófica, cabalística, cósmica, eixo do mundo. Há tantas. Há uma identidade simbólica entre árvore e indivíduo e sua alma (p.3).

Para isso, os estudos fenomenológicos são de grande relevância, auxiliando a ultrapassar o que Norberg-Schulz chama de "esquecimento do Ser", que tanto caracteriza nossa época contemporânea.

Esperamos, assim, que, por meio dessas reflexões ou descrições, possamos contribuir com um novo olhar sobre as árvores urbanas, auxiliando na compreensão da carga imaginária que lhes é inerente. É intenção que estas questões subjetivas deixem de ser alijadas do processo projetual de planejamento urbano sem detrimento das questões técnicas, sugerindo de forma efetiva para a construção de paisagens mais humanas, nas quais os valores simbólicos da árvore sejam valorizados em toda a sua plenitude.

Assim, a árvore vem revelar na paisagem urbana múltiplas imagens. Rainer Maria Rilke (1927, p. 29 citado por Bachelard, 1978, p. 219), em seu poema, "Vergers" sente e expressa bem que a árvore "é o eixo em que o sonhador passa mais normalmente do terrestre ao aéreo".

Bachelard (1978) nos ensina que:

Um dos encantos da fenomenologia da imaginação poética é poder viver uma nuança nova diante de um espetáculo que convida a conhecer a existência do ser arbóreo. [...] Se a nuança é sinceramente vivida pelo poeta, o fenomenólogo está certo de captar um ponto de partida da imagem (p. 208).

Para realizar plenamente o seu "Ser" existencial, os sujeitos precisam entrar em uma relação dialógica com o mundo (lugar). É o mundo através dos seus fenômenos e acontecimentos do cotidiano que se dirige a nós, pois tudo o que nos acontece diz algo sobre nós mesmos de uma forma única e singular.

Rev. Nufen: Phenom. Interd. | Belém, 11(1), 157-177, jan. - abr., 2019. 
Precisamos perceber e aceitar a alteridade do "Ser" na sua totalidade, na sua unidade e na sua unicidade. É importante que se torne presença significativa para nós, uma vez que o diálogo genuíno só pode se dar sobre a plena reciprocidade da linguagem (palavra), quando cada sujeito experiência a relação também do outro lado do outro.

Martim Buber (2009), em sua obra Do Diálogo e Do Dialógico, nos chama à reflexão no sentido de compreender que não é significativo apenas o relacionamento dos sujeitos entre si, mas o seu comportamento e sua atitude de "mim-para-com-o outro" e em relação a outros seres.

Em Espaço e Lugar: a perspectiva da experiência, o geógrafo humanista, Yi-Fu Tuan reforça esse modo de conceber o aprendizado, visto que "experienciar significa atuar sobre o dado e criar a partir dele. $O$ dado não pode ser conhecido em sua essência. $O$ que pode ser conhecido é uma realidade que é um constructo da experiência, uma criação de sentimento e pensamento" (Tuan, 1983, p. 10).

Em nome da experiência, o poema de Ferreira Gullar (2004) trilha caminhos apreendidos a partir da própria vivência, no qual o poeta resvala pelo sentimento de topofilia abrangendo o imaginário social do lugar-árvore na cidade (

Figuraigura 2).

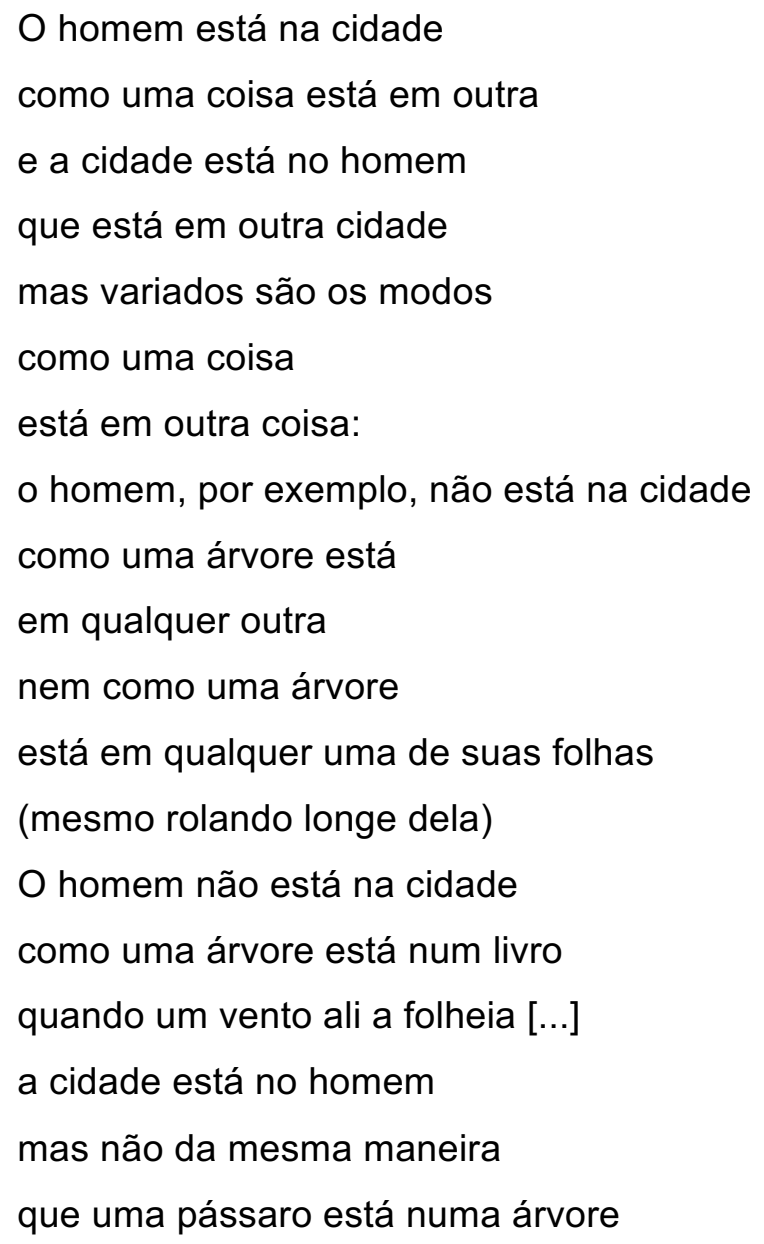

Rev. Nufen: Phenom. Interd. | Belém, 11(1), 157-177, jan. - abr., 2019. 
não da mesma maneira que uma pássaro

(a imagem dele)

está na água

e nem da mesma maneira

que o susto do pássaro

está no pássaro que eu escrevo

a cidade está no homem

quase como a árvore voa

no pássaro que a deixa

O homem está na cidade como uma coisa... (Gullar, 2004, p. 147-149)

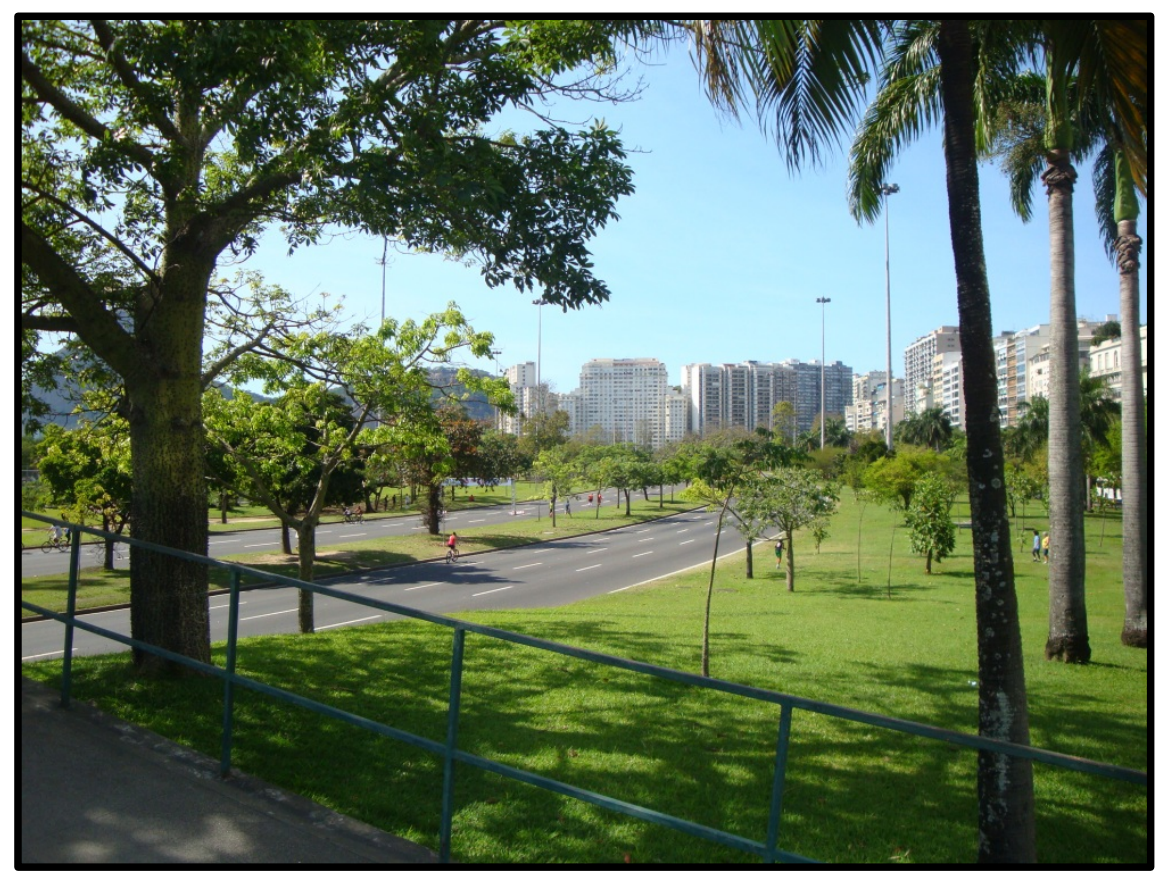

Figura 2: Parque do Flamengo: lugar-árvore. 2013. Foto de Jorge Crichyno.

\section{REFERÊNCIAS}

Bachelard, G. (2004). La Flamme d'une Chandelle. Paris: Quadrige/ PUF. $4^{\circ}$ ed. (2001). O ar e os sonhos: ensaio sobre a imaginação do movimento. São Paulo: Martins Fontes.

. (1978). A poética do espaço. In Os Pensadores, São Paulo: Abril

Cultural, pp. 181-354.

. (1960). La poétique de la rêverie. Paris: Presses Universitaires de France.

Rev. Nufen: Phenom. Interd. | Belém, 11(1), 157-177, jan. - abr., 2019. 
Buber, M. (2009). Do diálogo e do dialógico. São Paulo: Perspectiva.

Cecchin, G. (1991). Nova Perspectiva Sistêmica. ano VI, n. 10, Rio de Janeiro, pp. 6-15, ago. 1997. Apresentação no Encontro Internacional Novos Paradigmas, Cultura e Subjetividade, Buenos Aires.

Cerbone, D. R. (2013). Fenomenologia. Tradução de César Souza. Petrópolis, RJ: (Série Pensamento Moderno).

Brosse, J. (1998). Posface: The Life of Trees. In: Rival, L. (Ed.) The social life of trees: antrophological perspectives on tree symbolism. New York: Berg, pp. 299-303.

Buttimer, A. (1985). Aprendendo o dinamismo do mundo vivido. In Christofoletti, A. C. (org.). Perspectivas da Geografia. São Paulo: Difel, pp. 165-193.

Cosgrove, D. E. (1978). Place, landscape, and the dialectics of cultural geography. Canadian Geographer, v. 22, pp. 66-72.

Cullen, G. (1983). Paisagem urbana. Lisboa: Edições 70.

Daniels, S. \& Cosgrove, D. (2002). Introduction: Iconography and Landscape. In Cosgrove, D. \& Daniels, S. (Ed.) Iconography and landscape: essays on the symbolic representation, design and use of past enviromnents. Cambridge Studies in Historical Geography. Cambridge: University Press, pp. 1-10.

Dardel, E. (2011). O homem e a terra: natureza da realidade geográfica. Tradução de Werther Holzer. São Paulo: Perspectiva.

Dell, P. (1985). Understanding Batrson and Maturana: towards a biological foundation for social sciences. Washington.

Detzel, V. A. (1992). Avaliação da opinião pública sobre a arborização de maringá, PR. In Siqueira, E. S.; Wandembruck, A. \& Mores, M.(Org.). In I Congresso Brasileiro sobre Arborização Urbana, $4^{\circ}$ Encontro Nacional sobre Arborização Urbana, v. 2, 1992 , Vitória. Anais ... Vitória: Prefeitura de Vitória/Cia. Vale do Rio Doce, pp. 327-342.

Dorfles, G. (1975). Mythes et rites d’Anjourd ’hui. Paris: Klincksiek.

Dwyer, J.; Schoeder, H. \& Gobster, P. (1994). The Deep Significance of Urban Trees and Forest. In Platt, R.; Rowntree, R. \& Muik, P. (Ed.). The ecological city: preserving and restoring urban biodiversity. Massachusetts: The University of Massachusetts Press, pp. $137-150$.

Vasconcellos, M. J. (2013). Pensamento sistêmico: o novo paradigma da ciência. Campinas: Papirus.

Foerster, H. (1991). Cibernética de la cibernética. In Packman, M. Las semillas de la cibernética. Obras escogidas de Heinz von Foerster. Barcelona: Gedisa, pp. 89-93. (Original publicado em 1974).

Furtado, A. E. (1994). Simulação e análise da utilização da vegetação como anteparo às radiações solares em uma edificação. (Dissertação de Mestrado em Arquitetura) Faculdade de Arquitetura e Urbanismo, Universidade Federal do Rio de Janeiro, Rio de Janeiro. 
Gambini, R. (1997). Árvore e alma, in Hypnos, ano 1, n. 2, p. 58-68. Recuperado em 20 de fevereiro de 2019, de

http://www.hypnos.org.br/revista/index.php/hypnos/article/viewFile/267/288

Gullar, F. (2004). Melhores poemas. São Paulo: Global.

Heidegger, M. ( 2013). Ontologia (hermenéutica da faticidade). Tradução de Renato Kirchner. Petrópolis, RJ: Vozes.

Petrópolis, RJ: Vozes.

Holzer, W. (2010). O método fenomenológico: humanismo e a construção de uma nova Geografia. In Corrêa, R. L. \& Rosendahl, Z. (Orgs.). Revista de Geografia Cultural. Rio de Janeiro: EDUERJ, pp. 37-71.

Hull, R. B. (1992). How the public values urban forests. Journal of Arboriculture. v. 18, n. 2, pp. 98-101.

Lynch, K. (1997). A imagem da cidade. São Paulo: Martins Fontes.

(1972). What time is this place? Cambridge: MIT.

Lyotard, J. (s.d.). A fenomenologia. Lisboa: Edições 70.

Maturana, H. (1990). O que se observa depende do observador (1987). In Thompson, W. I. (org.). Gaia: uma teoria do conhecimento. São Paulo: Gaia.

(1997). Realidade: a busca da objetividade, ou a procura de um conhecimento coercitivo (1988). In Maturana, H. A Ontologia da Realidade. Belo Horizonte: Editora da UFMG.

Merleau-Ponty, M. (1964). Le visible e et l'invisible. Paris: Gallimard.

. (1994). Fenomenologia da percepção. Rio de Janeiro: Martins Fontes. . (2000). A natureza. Trad. Álvaro Cabral. São Paulo: Martins Fontes.

Morin, E. (2001). Amor, poesia sabedoria. Tradução de Edgar de Assis Carvalho. Rio de Janeiro: Bertrand. Brasil.

Norberg-Schulz, C. (1980). Genius loci-towards a phenomenology of archicteture. New York: Rizzoli International Publications.

Relph, E. C. (1976). Place and placenessless. London: Pion. 156p. (1979). As bases fenomenológicas da geografia. Geografia, 4 (7): 1-25.

Ribeiro, W. C. (1993). Do lugar ao mundo ou o mundo no lugar? Terra Livre AGB, 11-12: 237-242.

Rilke, R. M. (2001). Poèmes Français. In Bachelard, G. O ar e os sonhos: ensaio sobre a imaginação do movimento. São Paulo: Martins Fontes.

Sattler, M. A. (1992). Arborização urbana e conforto ambiental. In Siqueira, E. S.; Wandembruck, A. \& Mores, M. (Org.). In I Congresso Brasileiro sobre Arborização 
Urbana, $4^{\circ}$ Encontro Nacional sobre Arborização Urbana, v. 2, Vitória. Anais ... Vitória: Prefeitura de Vitória/Cia. Vale do Rio Doce, v. 2, pp. 15 - 28.

Schroeder, H. W. (1990). The psychological value of trees. The Public Garden, v. 6, n. 1, pp. 17-19, janeiro.

Silva, C. A. F. (2013). Manipular ou habitar? Merleau-Ponty e o paradoxo da ciência, in Filosofia Unisinos 14(1): 84-99, jan/abr. Recuperado em 20 de fevereiro de 2019, de http://revistas.unisinos.br/index.php/filosofia/article/view/fsu.2013.141.07

Stiegler, J. H. (1990). Public perceptions of the urban forest. In Rodbell, P. D. (Ed.). Make our cities safe for trees: Proceedings of the Fourth Urban Forestry Conference.

Washington: The American Forestry Association. pp. 40-45.

Tuan, Y. (1975). Place: an experiential perspective. Geographical Review, 65 (2): pp. 151165. . (1983). Espaço e lugar. São Paulo: Difel, 250p.

\section{NOTAS SOBRE O AUTOR:}

Jorge Crichyno. Professor Doutor do Departamento de Urbanismo da UFF. Universidade Federal Fluminense. E-mail: jorgecrichyno@hotmail.com.

Recebido em: 09/09/2018.

Aprovado em: 14/03/2019. 